\title{
Adaptive Reward Pursuit: How Effort Requirements Affect Unconscious Reward Responses and Conscious Reward Decisions
}

\author{
Erik Bijleveld \\ Utrecht University
}

\author{
Ruud Custers \\ University College London and Utrecht University
}

\author{
Henk Aarts \\ Utrecht University
}

\begin{abstract}
When in pursuit of rewards, humans weigh the value of potential rewards against the amount of effort that is required to attain them. Although previous research has generally conceptualized this process as a deliberate calculation, recent work suggests that rudimentary mechanisms-operating without conscious intervention-play an important role as well. In this article, we propose that humans can perform a basic integration of reward value and effort requirements without conscious awareness. Furthermore, we propose that conscious awareness of rewards allows for the use of more advanced functions in reward pursuit, which consider the specific course of action that leads to reward attainment. Using a monetary reward priming paradigm that allows us to dissect the performance effects of rewards (i.e., coins of different value) into conscious and unconscious components, we tested this proposal in 3 experiments. Overall, results indicate that people rely on a simple yet adaptive mechanism that unconsciously conserves effort during reward pursuit, because it makes people more reward sensitive whenever more effort is required of the body. Moreover, consciousness supports a more sophisticated mode of reward pursuit, via which people can strategically conserve effort even further. We discuss these findings in the context of decision making, motivation, and consciousness.
\end{abstract}

Keywords: rewards, effort requirements, (un)conscious processing, motivation

As a consequence of their adaptation to the environment, animals can effectively execute behaviors to attain rewards. Humans are no exception to this, as they are well-equipped to pursue rewards like food, drink, and money. Although the activities that are instrumental to reward attainment (e.g., grasping, running, or even thinking) may vary widely in nature, all have at least some energetic costs. In other words, it takes effort to attain rewards, which is why people weigh the value of rewards against the amount of effort that is required to attain them. Such weighing seems to be an intricate process that involves the careful, conscious integration of multiple features of the environment. But is consciousness indeed a necessary condition for this functionality to operate? With the present research, we explore this question.

Although research has generally characterized the integration of rewards and effort requirements as deliberate calculations, we

This article was published Online First April 2, 2012.

Erik Bijleveld, Department of Psychology, Utrecht University, Utrecht, the Netherlands; Ruud Custers, Cognitive, Perceptual, and Brain Sciences, University College London, London, England, and Department of Psychology, Utrecht University; Henk Aarts, Department of Psychology, Utrecht University.

The work in this article was supported by Grants VENI 451-06-014 and VICI 453-06-002 from the Netherlands Organization for Scientific Research.

Correspondence concerning this article should be addressed to Erik Bijleveld, Department of Psychology, Utrecht University, P.O. Box 80140, 3508TC Utrecht, the Netherlands. E-mail: e.h.bijleveld@uu.nl propose that the underlying mechanisms can be very rudimentary. This idea is based on research showing that the same functionality can also be observed in nonhuman animals (e.g., van den Bos, van der Harst, Jonkman, Schilders, \& Spruijt, 2006) and on research showing that some of the brain structures that are central to this functionality are evolutionarily very old, operating independently of consciousness (Delgado, 2007; Salamone, Correa, Farrar, Nunes, \& Pardo, 2009). Such research raises the intriguing suggestion that people may be able to integrate reward information and effort requirements without conscious awareness.

In the current work, we address this possibility by testing a novel perspective on the (un)conscious nature of the human response to rewards. In essence, we propose that whenever effort requirements are detected by the body, people become more sensitive to the value of rewards, in that they invest effort especially when valuable (vs. less valuable) rewards are at stake. Accordingly, this unconscious mechanism operates in line with the basic idea that when more effort is required, only valuable rewards are sufficient compensation. Subsequent to such simple but adaptive processing, rewards sometimes enter conscious awareness. In that case, they additionally prompt reward decisions (Bijleveld, Custers, \& Aarts, 2010). In line with work on conscious motivation (Brehm \& Self, 1989), we propose that such reward decisions serve to prevent unwarranted expenses of effort in an advanced way, by adjusting and overruling unconscious modulations of reward sensitivity.

If this perspective is true, it would challenge the traditional assumption that flexible behavior is exclusively caused by con- 
scious and deliberate decisions. Instead, it would suggest that people are able to integrate cues from the environment and from the body (reward value, effort requirements) in an unconscious manner, resulting in the adaptive regulation of effort output - even though this occurs via a relatively simple mechanism. At the same time, we delineate a specific role for consciousness. By bridging the field of motivation and recent work on conscious versus unconscious processing, our current research has implications for the general understanding of how people act on rewards.

\section{Reward Pursuit: With and Without Conscious Awareness}

In the past century, psychologists have devoted ample attention to effects of rewards on human behavior, often addressing reward effects on task performance. Not surprisingly, research has generally confirmed the basic idea that the higher a reward is valuated, the more effort is invested in attaining it (see Bargh, Gollwitzer, \& Oettingen, 2010, for a review).

In typical experiments addressing this issue, humans consciously anticipate a reward (e.g., due to reward cues or reward instructions) that is contingent on their performance on some subsequent task. In line with lay beliefs, it is generally found that, via effort, the anticipation of a reward enhances performance in a wide variety of domains, such as physical exertion (Treadway, Buckholtz, Schwartzman, Lambert, \& Zald, 2009), cognitive control (Krebs, Boehler, \& Woldorff, 2010; Veling \& Aarts, 2010; Watanabe, 2007), creativity (Eisenberger \& Aselage, 2009; Glucksberg, 1962), and attention (Engelmann \& Pessoa, 2007; Kiss, Driver, \& Eimer, 2009). Although there are exceptions (e.g., Ariely, Gneezy, Loewenstein, \& Mazar, 2009; Beilock, 2010), rewards appear to have a widespread, facilitatory influence on human functioning (Bonner \& Sprinkle, 2002; Camerer \& Hogarth, 1999).

Recent research in cognitive neuroscience revealed that reward valuations are correlated with neural activity in the striatum. This subcortical structure mirrors the reward value of all kinds of stimuli, including money that can be earned (Bjork \& Hommer, 2007); also, it connects to many other brain structures, including those that support goal-directed action (Aston-Jones \& Cohen, 2005; Delgado, 2007; Knutson, Delgado, \& Phillips, 2008). It is important to note that the striatum is thought to have developed early in human evolution, and it has the same general structure and function across vertebrates. This idea provoked the suggestion that basic responses to rewards may not need conscious awareness, which is a faculty that is thought to have arisen relatively recently (e.g., Donald, 2001).

Pessiglione et al. (2007) tested this idea using a novel reward priming paradigm. In an experiment, people were exposed to coins (of high vs. low value), some of which they could earn by squeezing a handgrip: The harder they squeezed, the greater the proportion of the coins they received. It was not surprising that people squeezed harder when the coins were more valuable. Sometimes, however, coins were presented very briefly, so that they could not be consciously perceived (i.e., they were subliminally presented). Remarkably, even in this case, people worked harder when a more valuable coin was at stake, leading to the intriguing discovery that rewards do not need to be consciously perceived to trigger the recruitment of effort (for replications, see Bijleveld, Custers, \&
Aarts, 2009, 2010, 2011; Capa, Bustin, Cleeremans, \& Hansenne, 2011; Schmidt, Palminteri, Lafargue, \& Pessiglione, 2010; Zedelius, Veling, \& Aarts, 2011; for a review, see Bijleveld, Custers, \& Aarts, in press).

\section{Adaptive Reward Pursuit: With and Without Conscious Awareness?}

However, and like all other species that have successfully adapted to their environment, humans need to spend effort strategically-or, in other words, only when this is functional for attaining valuable rewards. Indeed, research on conscious motivation has identified various ways in which people integrate reward value and effort requirements to conserve effort while still attaining valuable rewards. In short, extensive evidence supports the ideas that people (a) are unlikely to spend more effort than is warranted by the reward and (b) are unlikely to spend more effort than is necessary given the effort requirements of the task that leads to reward attainment (Brehm \& Self, 1989; Gendolla, Wright, \& Richter, 2011; Wright, 2008). For example, such conscious processes induce people to withhold effort for rewards that are consciously judged to be not sufficiently valuable, given the amount of effort that is required to attain them (Eubanks, Wright, $\&$ Williams, 2002). But does basic integration of reward value and effort requirements already take place on an unconscious level? This central question remains.

One possibility is that rewards, upon perception, directly and unconsciously prompt the recruitment of effort. When the reward enters consciousness, then, effort may be further regulated after deliberate cost-benefit analyses, which are based not only on conscious information about the reward's value but also on the effort requirements. Although this idea seems in line with research on the regulation, channeling, and control of initial reactions (e.g., Epley, Keysar, Van Boven, \& Gilovich, 2004; Gilbert, Pelham, \& Krull, 1988; Strack \& Deutsch, 2004), such a mechanism would be inefficient in that it would frequently lead to the unconscious, superfluous recruitment of effort.

A second possibility is that a basic integration of reward information and effort requirements may already take place without conscious awareness. Indeed, research has shown that people have several ways in which they keep track of the amount of effort that they currently expend, not necessarily with the aid of conscious awareness (Marcora, 2009). This idea raises the possibility that the human reward response is modulated to fit the current requirements of the situation. More specifically, people may differentiate more strongly between rewards of different value whenever more effort is required (Bijleveld et al., 2009). Such a modulatory mechanism would lead people to respond to rewards most strongly when this is likely to be most necessary - that is, when the organism detects (not necessarily with conscious awareness) that the current situation demands effort. Conversely, in situations that feel less demanding, people would respond equally strongly to rewards that are high versus low in value. This makes sense, as in this case, rewards are generally easier to get, making their value less relevant.

Currently, the evidence for the existence of such an unconscious, modulatory mechanism is circumstantial at best. Suggestive evidence comes from a previous study (Bijleveld et al., 2009) in which people were rewarded for successfully maintaining and reporting back digit strings that were either short (three digits) or 
long (five digits). Similar to the work on reward priming addressed above (Pessiglione et al., 2007), participants were first exposed to coins that they earned by correctly reporting the digits. As revealed by pupil dilation, which is a physiological measure of mental effort, high-value subliminal rewards prompted more effort only on the relatively difficult trials, that is, on the trials in which digit strings were long (Bijleveld et al., 2009). Although these findings suggest that effort requirements and reward values can be integrated on an unconscious level, they do not show that these integrations affect behavioral outcomes (e.g., related to performance). Furthermore, this study did not examine whether and how these integrations may occur differently for unconscious reward responses and conscious reward decisions. The present research addresses both of these issues.

Research from other fields is consistent with the possibility that the integration of effort requirements and reward may take place unconsciously and that it may rely on current bodily feedback of how much effort is required. For example, animals, such as rodents, that are assumed to have limited conscious experience and limited higher cognitive capabilities still effectively integrate effort requirements and rewards (e.g., van den Bos et al., 2006). More specifically, rats' reward-directed behavior is strongly determined by the subcortical dopamine neurons that target the ventral striatum (especially the nucleus accumbens), which is involved in emitting a reward signal to the rest of the brain (Phillips, Walton, \& Jhou, 2007; Salamone et al., 2009) and which receives direct input from brain structures that track effort requirements (e.g., the anterior cingulate cortex; Walton, Kennerley, Bannerman, Phillips, \& Rushworth, 2006). This suggests that conscious deliberation - a process often thought to be associated with specific processes in the frontal and parietal lobes of the cortex (Dehaene, Changeux, Naccache, Sackur, \& Sergent, 2006; Lamme, 2006) - may not be necessary for modulations of the reward response to take place. Instead, basic modulations of reward sensitivity may be rudimentary and may occur independently of conscious awareness.

More generally, other research is consistent with the idea that the demands that are imposed on the body inform various aspects of information processing (Preston \& Wegner, 2009). For example, such demands have been shown to affect various judgments (Jostmann, Lakens, \& Schubert, 2009; Proffitt, 2006). Similarly, effort requirements have been found to serve as a marker for which actions are one's own and which are not (Preston \& Wegner, 2007). Often explained from theories of embodied cognition (Barsalou, 1999; Niedenthal, Barsalou, Winkielman, Krauth-Gruber, \& Ric, 2005), these studies suggest that effort requirements are an important source of information. By extension, this research fits well the idea that unconscious, reward-related processes may depend on current bodily information about effort requirements. Our main aim in the present work is to test this novel hypothesis.

\section{A Specific Role for Conscious Processing}

Although previous work on motivation has often assumed that consciousness is crucial for weighing the pros and cons of actions (Bargh et al., 2010), the research addressed above thus suggests otherwise. Yet, this is not to say that consciousness has no additional function at all in the human pursuit of rewards. Recent research showed that when rewards enter conscious awareness, they trigger reward decisions over and above the basic recruitment of additional effort (Bijleveld et al., 2010). Indeed, several lines of research suggest that only consciously perceived stimuli gain access to a widespread frontal-parietal brain network that modulates and coordinates the operation of other brain structures, thereby enabling people to make strategic decisions about how they deal with tasks (Baars, 2002; Bijleveld et al., 2010; Dehaene \& Naccache, 2001; Van den Bussche, Segers, \& Reynvoet, 2008). Although adaptive behavior may well be produced without these functions (see our main hypothesis and, e.g., Lau \& Rosenthal, 2011), it is possible that these strategic decisions play an additional role in reward pursuit (Wallis \& Kennerley, 2010). Adjusting and perhaps even overruling unconscious modulations of reward sensitivity, such conscious decisions may help people to pursue rewards even more effectively (see Bargh \& Morsella, 2008).

The idea that people can rely on strategic decisions in their reward pursuit fits well with leading theories of reward-directed behavior, which suggest that people engage in calculations (e.g., based on expected value and effort requirements) to decide how much effort to invest (Brehm \& Self, 1989; Eccles \& Wigfield, 2002; Feather, 1982; Gendolla et al., 2011; Wright et al., 2008). Going beyond mere modulations of reward sensitivity, this decision-making process is indeed thought to be rather sophisticated. First, via conscious decisions, people may not just increase the expense of effort but may also suspend it altogether (for a review, see Gendolla et al., 2011). This has been found to occur when the reward is low in value-or, more specifically, when it is too low in value to justify the effort that is required to attain it. In such cases, in which reward pursuit is deemed uneconomical, people may refrain from investing effort likely because this saves effort for future, more fruitful opportunities to attain rewards. As such decisions to refrain are highly strategic in nature (e.g., they lead to deliberate disengagement from a task in the service of future opportunities), it is well possible that they specifically rely on higher level brain functions that are associated with conscious awareness (Dehaene et al., 2006; Van den Bussche et al., 2008).

Second, conscious decisions take into account not just any bodily indication that effort is required; instead, theories of (conscious) reward pursuit suggest that reward decisions are more precise. That is, in determining how much effort to expend, people are thought to consider the expected value and the effort requirements of the specific course of action that leads to attainment of a reward (Eccles \& Wigfield, 2002). Relying on higher level brain functions (i.e., the frontal-parietal network mentioned above; Dehaene et al., 2006), conscious decisions are thus based on strategic calculations that go beyond mere modulations of reward sensitivity by any effort requirements. As effort requirements that relate to the attainment of rewards are selectively considered, conscious reward decisions may well be insensitive to effort requirements that are irrelevant - that is, that are not instrumental for attaining rewards. The strategic nature of conscious reward decisions may via this route protect reward pursuit from external, reward-unrelated influences.

Taken together, we propose that although reward pursuit can occur in a basic yet adaptive way outside of awareness, conscious reward decisions help people to pursue and attain rewards in a more sophisticated way. Our hypotheses are as follows: Most important, we expect that whenever people sense that more effort is required of the body, they respond more strongly to high-value 
(vs. low-value) rewards that are unconsciously perceived (Hypothesis 1). When rewards enter consciousness, however, we expect that reward pursuit occurs in a more sophisticated way. Specifically, we expect that consciously perceived rewards that are low in value lead people to refrain from investing effort, especially when they require a lot of effort to attain (Hypothesis 2). Finally, we expect that irrelevant effort requirements affect people's unconscious reward responses but not people's conscious reward decisions (Hypothesis 3).

\section{Present Research}

We developed a new reward priming paradigm to test our hypotheses. The paradigm was designed to meet two key requirements. First, it should directly measure effort, undiluted by cognitive task strategies and thoughts. We accommodated this by using a finger-tapping task in which the expense of effort directly translated into motor performance. Second, it should allow us to dissect unconscious reward responses from conscious reward decisions. For that reason, we used a reward priming procedure similar to that used in previous research, in which people are exposed to a coin that they can earn by successfully performing a task-finger tapping, in this case. The coins were either of high or of low value (10 cents vs. 1 cent $)^{1}$ and were presented in such a way that they could or could not be consciously perceived (supraliminal vs. subliminal). As a dependent measure of effort, we recorded finger-tapping speed; this was similar to measures of effort in previous research on effort in rodents and humans (Salamone, Cousins, McCullough, Carriero, \& Berkowitz, 1994; Treadway et al., 2009). Although the supraliminally presented but not the subliminally presented coins can be processed with conscious awareness, this procedure has proven useful for dissociating between unconscious and conscious aspects of reward processing (Bijleveld et al., 2010, 2011).

To test our main hypothesis (Hypothesis 1), we manipulated effort requirements in several ways across three experiments. In Experiment 1, we tested the basic idea that people differentiate more strongly between rewards of different value when they are explicitly instructed that an upcoming task requires a lot versus a little effort. In this experiment, we manipulated effort requirements such that participants had to complete the same fingertapping task in a short versus long time window (high vs. low required effort, respectively). This experiment served to replicate previous research in a different paradigm and to test whether we could effectively dissociate between unconscious and conscious reward-induced processes. Experiment 2 served to test the idea that the unconscious modulation of the reward response is based on current, momentary feedback about required effort (Hypothesis 1). Accordingly, while the design of Experiment 1 allowed participants to anticipate task demands, participants were able to experience effort requirements only during action in Experiment 2. Moreover, Experiment 2 allowed us to test Hypothesis 2. Finally, in Experiment 3, we removed the instrumental relation between required effort and reward attainment by manipulating effort requirements via a secondary, reward-irrelevant task. As this procedure defeats all conscious reasons to integrate reward value with effort requirements (i.e., they have nothing to do with each other), finding reward sensitivity to be modulated at the unconscious level would constitute strong evidence for the idea that this basic integration is independent of conscious deliberation (Hypothesis 1). Moreover, Experiment 3 was designed to test Hypothesis 3.

\section{Experiment 1}

\section{Method}

Participants and design. Thirty-five students (19 women, 16 men; mean age $=20.7$ years) were recruited to participate. Participants were compensated with the money they earned during the experiment, which was, on average, €4.92. The study used a 2 (reward value: 1 cent vs. 10 cents) $\times 2$ (reward presentation: supraliminal vs. subliminal) $\times 2$ (effort requirements: low vs. high) within-subjects design. Participants completed 96 trials in total, 12 repetitions per condition. The effort requirements factor was manipulated by blocks. As such, participants completed four blocks in which effort requirements were low and four blocks in which effort requirements were high, in alternating order. The type of the first block (low demands vs. high demands) was counterbalanced across participants.

Procedure. Participants worked individually on the task. They learned that on each trial, they would see a coin ( 1 cent or 10 cents; the reward value factor), which they could earn by tapping the $G$ key on the keyboard 25 times within a specified time limit. At times, so they were instructed, the coin would be "difficult to perceive." Accordingly, on half of the trials, the coin was presented subliminally (the reward presentation factor). In low-requirement blocks, participants received the coin if they tapped 25 times within $10 \mathrm{~s}$. In high-requirement blocks, participants had only $3.5 \mathrm{~s}$ to complete 25 taps. Before the experimental trials started, participants completed eight practice trials. At the beginning of each block, participants were clearly informed of the upcoming block's time criterion (i.e., whether the block would be a low-requirement or a highrequirement block).

Trials. The sequence of events in a trial is depicted in Figure 1. Each trial started when the participant pressed a key (the $A$ key for right-handed participants and the $L$ key for left-handed participants). Next, they saw a fixation cross. Then, participants saw a coin, masked in such a way that it either was or was not consciously perceptible (see Figure 1). After another fixation cross appeared, the tapping part of the trial started. Specifically, people saw a row of 25 open circles $(O)$, which indicated that they had to start tapping. With each tap, one of the open circles became an X, starting from the left. This way, participants could keep track of their progress; when there were no open circles left, this indicated that participants were finished tapping. Next, participants received feedback on their performance (whether they met the criterion and how fast they tapped). When their tapping time was below the set criterion ( 10 or $3.5 \mathrm{~s}$ ), the value of the reward was added to their cumulative earnings, which were shown at the final screen of the trial. Then, a new trial started.

The experiment was programmed such that participants had to hold the $A$ key or $L$ key throughout the trial, to ensure that tapping

\footnotetext{
${ }^{1}$ The coins used in the experiments were Euro currency. The value of 10-cent and 1-cent Euro coins is approximately the same as the value of American dimes and pennies, respectively.
} 


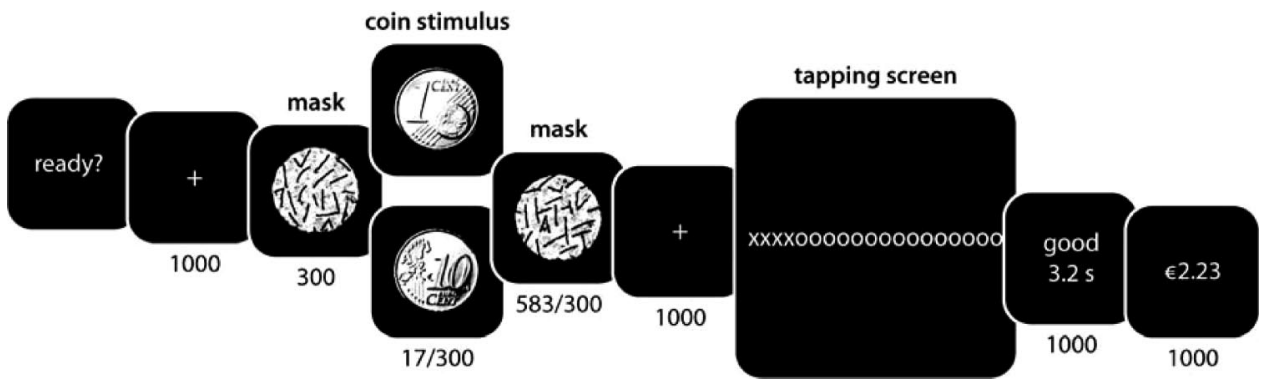

Figure 1. The course of a trial (Experiment 1). Numbers represent presentation durations in milliseconds. A duration of $17 \mathrm{~ms}$ corresponds to the duration of one frame on a 60- $\mathrm{Hz}$ monitor. In all conditions, the duration of the coin and the masks added up to $900 \mathrm{~ms}$.

could only be performed with one hand. On the basis of the well-supported idea that faster tapping consumes more effort (e.g., Treadway et al., 2009), we operationalized effort expense as the time in which participants tapped 25 times.

Subliminality of coins. Subliminality of the stimuli was confirmed in a separate signal detection task with 30 different participants. On each trial, participants saw a coin ( 1 cent vs. 10 cents), presented in the same way as in the experiment (17 ms vs. $300 \mathrm{~ms}$ between masks). After each of the 80 coins, participants indicated the value of the coin. When coins were presented for 17 $\mathrm{ms}$, detection accuracy did not deviate from chance, $M=51.1 \%$, $t(29)=0.68, p=.502 .^{2}$ When coins were presented for $300 \mathrm{~ms}$, however, participants could accurately report their value, $M=$ $99.3 \%, t(29)=209.2, p<.0001$.

\section{Results}

We analyzed tapping times as a function of reward value, reward presentation, and effort requirements. Trials more than 3 standard deviations from the mean of the high-demand or the low-demand condition were deleted, which resulted in the exclusion of $1.3 \%$ of trials. ${ }^{3}$ Mean tapping times were submitted to a repeated-measures analysis of variance (ANOVA) according to the design (see Figure 2). This yielded a main effect of reward value, $F(1,34)=13.5, p=.001, \eta_{\mathrm{p}}^{2}=.29$, revealing that participants tapped faster when more was at stake. Also, there was a main effect of reward presentation, $F(1,34)=8.0, p=.008, \eta_{\mathrm{p}}^{2}=.19$, indicating that participants tapped faster when coins were presented subliminally. Moreover, there was a main effect of effort requirements, $F(1,34)=104.2, p<.001, \eta_{\mathrm{p}}^{2}=.75$, indicating that participants were faster when effort requirements were high. As predicted, these effects were qualified by the Reward Value $\times$ Effort Requirements interaction, $F(1,34)=14.8, p<.001, \eta_{\mathrm{p}}^{2}=$ .30. In line with Hypothesis 1 , this interaction indicated that people responded more strongly to rewards when effort requirements were high, compared with when they were low (see Figure 2). Crucially, this interaction was not only present for the supraliminal coins, $F(1,34)=12.16, p=.001, \eta_{\mathrm{p}}^{2}=.26$, but also for the subliminal coins, $F(1,34)=4.4, p=.044, \eta_{\mathrm{p}}^{2}=.11$. Thus, these data support the idea that modulations of reward sensitivity by effort requirements are not dependent on conscious awareness.

The latter tests suggest that the interaction was stronger for the supraliminal coins. This suggestion is supported by the presence of the Reward Value $\times$ Reward Presentation $\times$ Effort Requirements three-way interaction, $F(1,34)=8.3, p=.007, \eta_{\mathrm{p}}^{2}=.20$. The presence of this interaction is in line with the hypothesis that it is only via conscious reward decisions that people may refrain from investing effort when the reward is particularly low in value (i.e., Hypothesis 2; Brehm \& Self, 1989; Wright, 2008). Indeed, the pattern of means (see Figure 2) suggested that people were especially slow for consciously perceived 1-cent coins when effort requirements were high. In this particular condition, participants were much slower than they were in any of the other high-effortrequirements conditions, as evidenced by $t$ tests of simple main effects, $t \mathrm{~s}(34)>3.2, p \mathrm{~s}<.003$.

\section{Discussion}

Experiment 1 showed that participants differentiated more strongly between high-value and low-value rewards in the face of a more demanding task. In line with Hypothesis 1, we also found this modulation for rewards that were presented subliminally. This finding thus points to the existence of an unconscious mechanism that serves the adaptive allocation of effort. While previous work on this mechanism was limited to physiological evidence (Bijleveld et al., 2009), we replicated this previous work using a different measure, supporting the validity of our finger-tapping paradigm. In line with Hypothesis 2, conscious reward decisions were different from unconscious reward responses, in that people expended little effort for low-value rewards, especially when these were consciously perceived.

\section{Experiment 2}

Although we proposed that unconscious reward responses are attuned to current, bodily effort requirements (Hypothesis 1), a potential alternative explanation for our findings may lie in the fact that people could consciously anticipate the effort requirements of upcoming trials and decide how to respond to rewards in advance, on the basis of that anticipation. One could argue

\footnotetext{
${ }^{2}$ We also explored whether people became better at detecting the subliminal coins after repeated exposure. To that end, we also computed accuracy separately for the early trials (i.e., the first half) and the late trials (i.e., the second half) of the subliminality check. A paired $t$ test indicated that people were equally accurate on early and late trials, $t(29)=0.71, p=.49$.

${ }^{3}$ This procedure did not substantially alter our conclusions.
} 

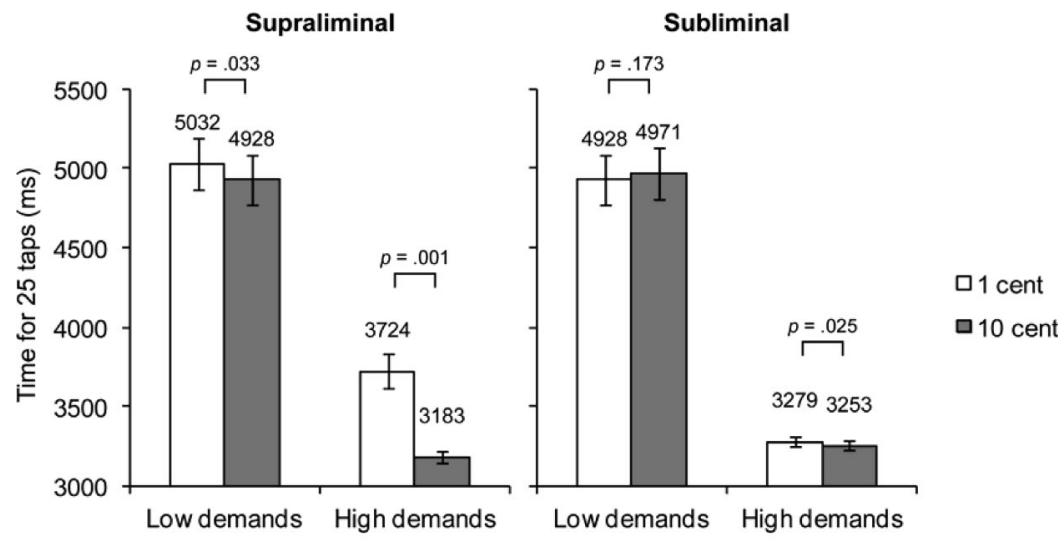

Figure 2. Results of Experiment 1. Mean tapping time (in milliseconds) for 25 taps is depicted as a function of reward value, reward presentation, and effort requirements. Error bars represent within-subjects standard errors of the mean (following the method suggested by Cousineau, 2005).

that the experimental blocks constituted different contexts (i.e., a high-effort-requirements context and a low-effortrequirements context), in which rewards evoked different responses to begin with.

Indeed, in several research domains, it has been shown that unconscious responses to stimuli may be contingent on the context they are presented in (Aarts \& Dijksterhuis, 2003; Bouton, 1993; Gawronski, Rydell, Vervliet, \& De Houwer, 2010; Wittenbrink, Judd, \& Park, 2001). For example, people who received successful exposure treatment for specific anxiety disorders (e.g., fear of spiders) may still relapse when they are faced with a fear-inducing stimulus (e.g., a spider) in a context in which their fearful responses used to occur (Bouton, 1993). In a similar vein, research from the area of prejudicial behavior shows that spontaneous responses to Black faces are different when the faces are presented against the backdrop of a church versus a street corner (Wittenbrink, Judd, \& Park, 2001). Following a similar rationale, one might explain the results from Experiment 1 as an effect of the experimental contexts of low- versus high-effort requirements. These contexts, manipulated by blocks in Experiment 1, may have predefined people's responses to rewards of different values. If such were true, it would mean that people may not truly respond to momentary effort requirements but rather configure their responses to rewards well in advance and in a rather static way. For that reason, Experiment 2 was designed such that effort requirements could be assessed only during action (i.e., during tapping) and no longer in anticipation of the task.

Furthermore, Experiment 1 showed that people did not expend much effort for consciously perceived low-value rewards, especially when a lot of effort was required to attain them. Although this finding is in line with the idea that people strategically refrain from investing effort via conscious reward decisions (Hypothesis 2 ), the findings of Experiment 1 do not provide an explicit demonstration of this phenomenon, as the task did not allow people to quit the investment of effort altogether (i.e., people always had to tap 25 times to continue to the next trial). Accordingly, Experiment 2 was designed such that people did not have to complete a fixed number of taps to complete the trial. Instead, they could make the strategic decision to refrain from investing effort at any time. This allowed us to test the idea that people suspend the expense of effort only when they consciously perceive low-value rewards, most markedly so when they detect that these low-value rewards require a lot of effort to attain.

In Experiment 2, participants were required to move a coin stimulus from the left to the right of the screen by repeatedly tapping the keyboard. When they did this within a fixed time limit ( $3.5 \mathrm{~s})$, they received the coin. On some trials, however, the coin would move somewhat faster in response to keyboard taps, compared with other trials. The difference between trials of different effort requirements being only slight, this manipulation of effort requirements was much more subtle than the manipulation used in Experiment 1. More important, this procedure denied participants the opportunity to predict the demands of trials beforehand. Furthermore, although all trials ended after $3.5 \mathrm{~s}$, participants could decide to stop tapping after any number of taps. This allowed us to more clearly characterize when people strategically refrained from investing effort.

\section{Method}

Participants and design. Forty-nine students (21 men, 28 women; mean age $=20.8$ years) were recruited to participate. Participants were compensated with the money they earned during the experiment, which was, on average, €4.54. The tapping task used a 2 (reward value: 1 cent vs. 10 cents) $\times 2$ (reward presentation: supraliminal vs. subliminal) $\times 3$ (effort requirements: low vs. medium vs. high) within-subjects design, comprising 96 trials in total, eight repetitions per condition. Trials were presented in two blocks of equal length.

Procedure. Participants learned that on each trial, they would see a blue square that quickly moved from the left to the right of the screen. Although this was not mentioned to the participants, the blue square always had the same speed: It moved from the left to the right edge of the screen in $3.5 \mathrm{~s}$. A coin appeared at the same time as the blue square. Participants could move this coin to the right by repeatedly tapping the $G$ key on the keyboard. When the coin reached the right edge of the screen before the blue square, participants would earn the coin, which was worth either 10 cents 
or 1 cent. Reward presentation (i.e., coin visibility) was manipulated in a similar way as in Experiment 1. On supraliminal trials, the coin was visible throughout the tapping part of the trial. On subliminal trials, the coin was briefly $(17 \mathrm{~ms})$ presented in between rapidly alternating masks, once every $300 \mathrm{~ms}$. More specifically, the following sequence of events was repeated for $3.5 \mathrm{~s}$ during each subliminal trial: Mask 1 (50 ms), Mask 2 (50 ms), Mask 1 (50 $\mathrm{m})$, Mask 2 (50 ms), Mask 1 (33 ms), coin stimulus (17 ms), and Mask $2(50 \mathrm{~ms})$. As such, participants were exposed to the coin stimulus once every $300 \mathrm{~ms}, 10$ times total. Although the location of the stimulus shifted with the taps of the participant, the coin was always preceded and trailed by masks at the exact same location.

Critically, on low-required-effort trials, participants had to tap 21 times within 3.5 s to keep up with the blue square; on mediumrequired-effort trials, 23 times; and, on high-required-effort trials, 25 times (thus aligning with the high-required-effort condition of Experiment 1). No mention of these variations was made to participants. Hence, they could only detect effort requirements in an online fashion.

Trials. The sequence of events in a trial is depicted in Figure 3. Each trial started with a black screen, after participants had pressed the $A$ key or the $L$ key). Next, a fixation cross appeared, followed by the tapping part of the trial. Specifically, a coin and a blue square appeared at the left edge of the screen. The square moved by itself from the left to the right, whereas participants had to move the coin by repeatedly tapping the $G$ key. After $3.5 \mathrm{~s}$, when the blue square had reached the right part of the screen, participants received feedback about their performance (i.e., whether they succeeded in keeping up with the square, which required 21 vs. 23 vs. 25 taps in 3.5 s, depending on the effort requirement manipulation). Finally, the participants' cumulative earnings were displayed. After a 1-s intertrial interval, a new trial started. Tapping time was kept constant in this experiment (i.e., unlike in Experiment 1, participants tapped for $3.5 \mathrm{~s}$ on every trial), but effort was operationalized as the proportion of trials on which participants met the reward-attainment criterion.

\section{Results}

Preliminary analysis. To verify whether our rather subtle manipulation of effort requirements was successful, we tested how many times people tapped in the fixed time window of $3.5 \mathrm{~s}$, as a function of this manipulation. In the low-required-effort condition, people tapped 20.6 times on average; in the medium-requiredeffort condition, people tapped 22.5 times on average; in the high-required-effort condition, people tapped 23.7 times on aver- age. These means were significantly different from one another, $F(2,96)=235.4, p<.001, \eta_{\mathrm{p}}^{2}=.83$, confirming that people indeed invested more effort when effort requirements were higher.

Main analyses. As tapping time was kept constant over conditions in Experiment 2, performance was operationalized as the proportion of trials on which participants met the demands of the task and thus attained the reward (see Figure 4). These proportions were submitted to an ANOVA according to the design. This analysis revealed a main effect of reward value, $F(1,48)=$ $30.6, p<.001, \eta_{\mathrm{p}}^{2}=.39$, indicating that participants performed better when a 10-cent (vs. 1 cent) coin was at stake. Also, there was a main effect of reward presentation, $F(1,48)=8.3, p=.006$, $\eta_{\mathrm{p}}^{2}=.15$, indicating that participants performed better when coins were presented subliminally. The main effect of effort requirements was also significant, $F(2,96)=46.7, p<.001, \eta_{\mathrm{p}}^{2}=.49$, revealing that participants more often met the criterion when it was lower. Replicating Experiment 1, these effects were qualified by the Reward Value $\times$ Effort Requirements interaction, $F(2,96)=$ 13.7, $p<.001, \eta_{\mathrm{p}}^{2}=.22$, which suggested that people respond more strongly to rewards as a function of increasing levels of effort requirements. To confirm this idea, we tested whether the linear contrast of effort requirements interacted with reward value. This appeared to be the case, $F(1,48)=35.7, p<.001, \eta_{\mathrm{p}}^{2}=.43$. Crucially, when tested separately, this interaction was present not only in the supraliminal condition, $F(1,48)=17.9, p<.001$, $\eta_{\mathrm{p}}^{2}=.27$, but also in the subliminal condition, $F(1,48)=5.5, p=.024, \eta_{\mathrm{p}}^{2}=.10$. This finding constitutes support for Hypothesis 1.

As in Experiment 1, these effects were qualified by a Reward Value $\times$ Reward Presentation $\times$ Effort Requirements three-way interaction that approached significance, $F(2,96)=2.9, p=.060$, $\eta_{\mathrm{p}}^{2}=.06$, which suggested that people decided to refrain from investing a lot of effort, especially after they consciously perceived a low-value reward. We now turn to a more direct test of this idea.

Refraining from investing effort. To test the prediction that only consciously perceived rewards that are low in value cause people to refrain from investing effort, most markedly when these require a lot of effort to attain (Hypothesis 2), we conducted more specific analyses. That is, we investigated the conditions under which people stopped tapping prematurely, that is, before they completed the 21-25 taps that were required for attaining the reward. First, we examined whether low-value rewards prompt people to refrain from investing effort directly on (conscious) perception of rewards. If such were the case, people should have a tendency to stop tapping immediately after they detect a low-value coin, that is, early in a trial. Second, we examined whether peo-

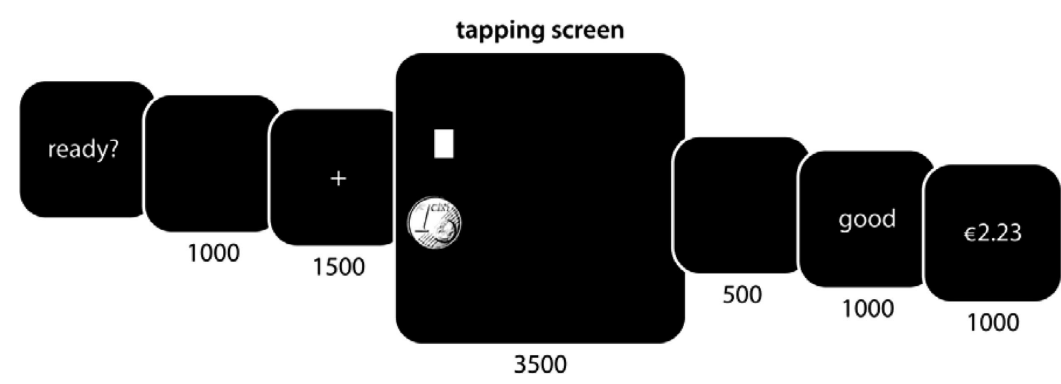

Figure 3. The course of a trial (Experiment 2). Numbers represent presentation durations in milliseconds. 


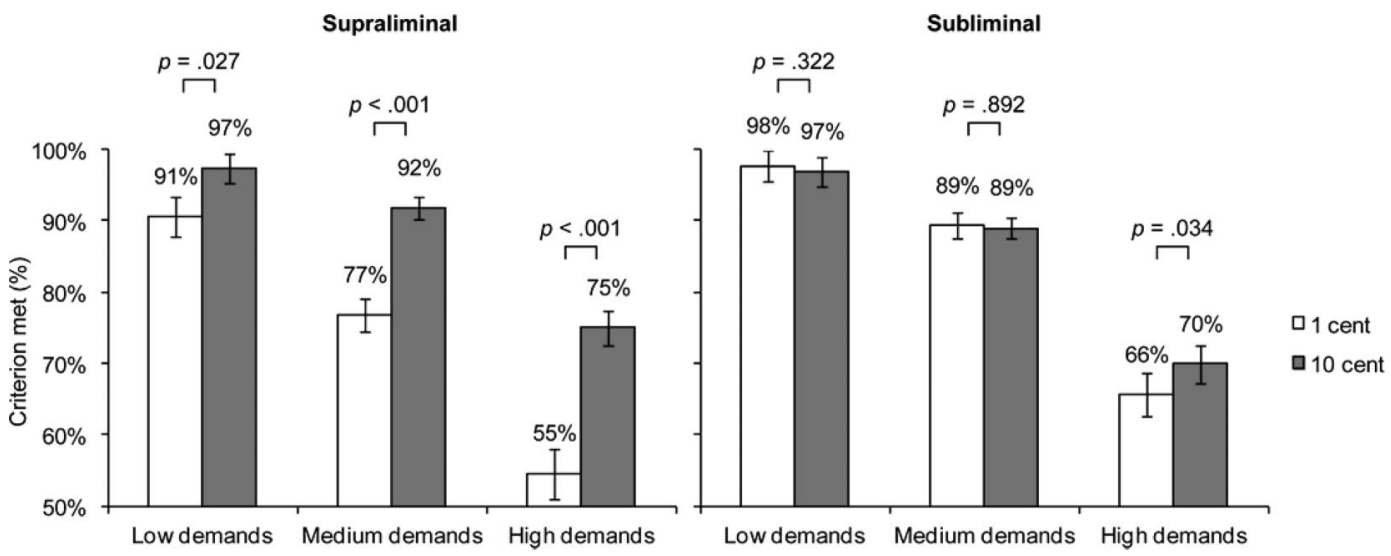

Figure 4. Results of Experiment 2. The proportion of trials in which the criterion was met is depicted as a function of reward value, reward presentation, and effort requirements. Error bars represent within-subjects standard errors of the mean (Cousineau, 2005).

ple's tendency to refrain from investing effort becomes stronger when the reward is not only low in value but also requires a lot of effort to attain. If such were the case, people should be inclined to stop tapping for conscious, low-value rewards, especially when they detect that attaining the reward takes a lot of effort, that is, later in a trial.

Stopping early in the trial. We reasoned that if it is true that people are inclined to suspend the expense of effort directly after they see that a low-value reward is at stake, they should stop tapping almost immediately after beginning a trial. To test this idea, we computed the proportion of trials in which people tapped five or fewer times for each condition of the design and tested effects of reward value and effort requirements for the supraliminal and subliminal presentation conditions separately. In the supraliminal condition, there was only an effect of reward value, $F(1$, $48)=5.27, p=.026, \eta_{\mathrm{p}}^{2}=.10$, indicating that people stopped tapping more often when they (consciously) perceived that a low-value reward was at stake. There was no effect of effort requirements, nor was there a Reward $\times$ Effort Requirements interaction, $F_{\mathrm{S}}<1$, suggesting that at this point people did not yet take into account whether effort requirements were low, medium, or high. In the subliminal condition, there were no significant effects, $F_{\mathrm{S}}<1$. This difference between conscious and unconscious reward pursuit was substantiated by a Reward $\times$ Presentation interaction, $F(1,48)=5.03, p=.030, \eta_{\mathrm{p}}^{2}=.10$, confirming that the main effect of reward was only present for supraliminally presented coins (see Figure 5 for specific tests). There was no Reward $\times$ Presentation $\times$ Effort Requirements three-way interaction, $F<1$, which is consistent with the idea that participants did not yet take into account effort requirements early in the trial. Supporting Hypothesis 2, this analysis thus demonstrates that low-value rewards lead people to refrain from investing effort, but only when they are consciously perceived. Moreover, this tendency proved to develop quickly — at least, before people might have taken into account effort requirements.

Stopping late in the trial. Furthermore, we tested the possibility that people's tendency to refrain from investing effort is even stronger when they detect that a low-value reward requires a lot of effort to attain (which would be in line with Experiment 1 and with previous research; e.g., Brehm \& Self, 1989). If such were the case, people should become even more likely to quit tapping for consciously perceived, low-value rewards after they notice that a lot of effort is required-that is, when the tapping trial is well under way. Accordingly, we also computed the proportion of trials in which people tapped 15 or fewer times for each condition of the design and tested effects in the supraliminal and subliminal presentation conditions separately. In the supraliminal condition, there was a main effect of reward, $F(1,48)=8.37, p=.006, \eta_{\mathrm{p}}^{2}=$ .15 , which again indicated that people stopped tapping early when a low-value reward was at stake. There was also a main effect of effort requirements, $F(1,48)=5.93, p=.019, \eta_{\mathrm{p}}^{2}=.11$. Inspection of the means, depicted in Figure 5, suggested that people's tendency to refrain from investing effort for low-value rewards was especially pronounced when effort requirements were high. To establish this pattern statistically, we tested a contrast of the low- and medium-effort requirements against the high-effortrequirements condition, which was significant, $F(1,48)=6.85$, $p=.012, \eta_{\mathrm{p}}^{2}=.13$. More important, this contrast interacted with reward, $F(1,48)=5.60, p=.022, \eta_{\mathrm{p}}^{2}=.10$, confirming that people's tendency to quit tapping for low-value rewards manifested most in the high-effort-requirements condition. In the subliminal condition, no effects were significant, $F<1$. Corroborated by a Reward $\times$ Presentation $\times$ Effort Requirements interaction that approached significance, $F(1,48)=3.00, p=.090, \eta_{\mathrm{p}}^{2}=.06$, and supported by more specific tests (see Figure 5), these findings indicate that people tend to refrain from investing effort only when a low-value reward is consciously perceived and that this effect is most pronounced when they detect that this low-value reward requires a lot of effort to attain (i.e., Hypothesis 2).

\section{Discussion}

Although participants could assess effort requirements only during action in Experiment 2, they still responded more strongly to high-value rewards when more effort was required. This finding reveals that modulations of reward sensitivity respond to momentary information about effort requirements (e.g., via visual feedback about their progress) and thus are presumably not caused by 
Supraliminal

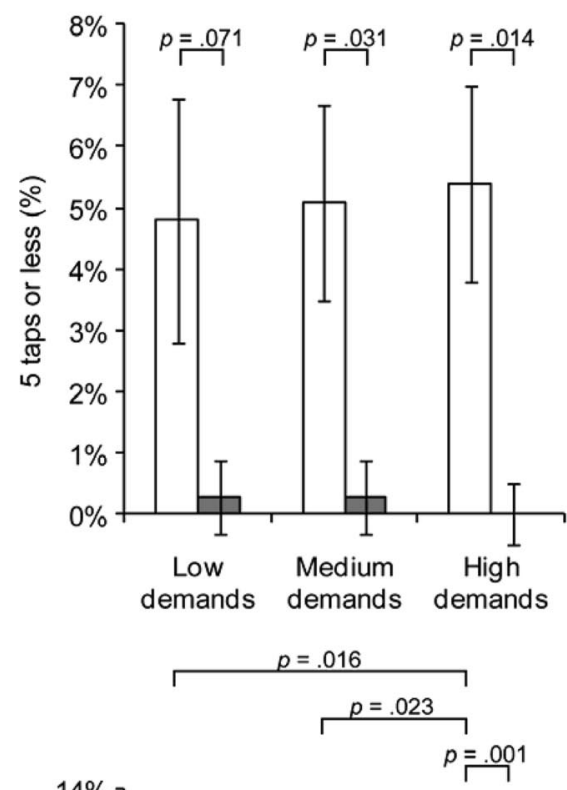

Subliminal
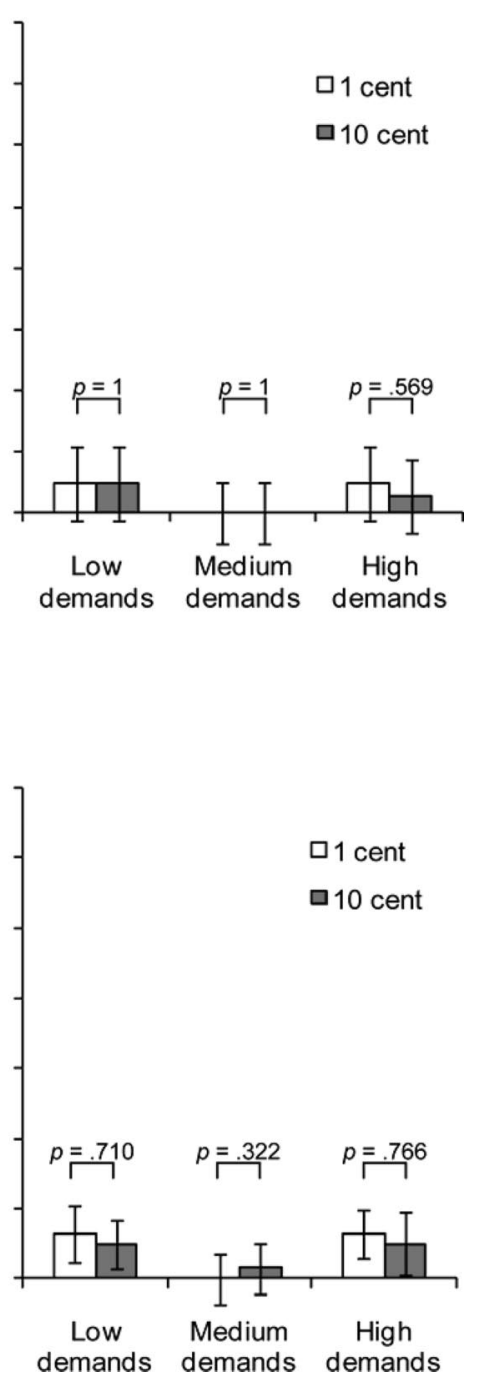

Figure 5. Results of Experiment 2. The proportion of trials in which people stopped early, that is, after tapping five or fewer times (top panels), and the proportion of trials in which people stopped later, that is, after tapping 15 or fewer times (bottom panels), depicted as a function of reward value, reward presentation, and effort requirements. Error bars represent within-subjects standard errors of the mean (Cousineau, 2005).

the experimental context. In support of Hypothesis 1, Experiment 2 further characterizes unconscious reward processing as adaptive - that is, unconscious reward responses facilitate the attainment of valuable rewards while being attuned to the current demands of the situation.

In support of Hypothesis 2, Experiment 2 further showed that only via conscious reward decisions do people refrain from investing a lot of effort when a low-value reward is at stake. Specifically, the present analysis suggests that a low-value reward may by itself increase people's tendency to refrain from investing effort (early in a trial, when behavior has be started) and that this tendency becomes more pronounced when people detect that a lot of effort is required to attain it (later in a trial, when behavior is well under way). The current study thus provides more compelling evidence for the idea that this classic effect (i.e., disengagement when a reward is not worth the effort; Brehm \& Self, 1989; Gendolla et al., 2011) is dependent on conscious reward processing.

\section{Experiment 3}

In the previous experiments and in line with most previous work on rewards and performance, the expense of effort was instrumentally and causally related to reward attainment. In other words, the tasks (and the instructions) were designed such that manipulations of required effort always pertained to a specific reward. At least in the domain of how people consciously pursue rewards, this way of addressing reward effects seems realistic and ecologically valid (Eccles \& Wigfield, 2002; Feather, 1982). For the present purposes, however, it leaves open the possibility that this causal instrumentality - as induced by conscious instructions-prepares 
people for the integration of rewards and effort requirements, as a part of the specific set of strategies that is evoked by the task and the related instructions (Dehaene et al., 2006). Accordingly, one might argue that the unconscious modulations that were identified in Experiments 1-2 were created by the experimental setting and are thus a specific consequence of the task rather than a basic human tendency.

To exclude the latter possibility, we designed Experiment 3. Pushing our manipulations of effort requirements one step further, we manipulated effort requirements so that they were unrelated to the reward outcome of the tapping task (cf. Preston \& Wegner, 2007). Specifically, participants were required to either forcefully squeeze or merely hold a handgrip with their nondominant hand. It is important to note that the effort requirements imposed by this manipulation were not instrumentally related to the reward that was at stake. By contrast, they could earn rewards with the fingertapping task that they completed concurrently with their dominant hand.

If Experiment 3 would show that effort requirements make people reward sensitive-even though they are unrelated to reward attainment in this experiment-this would support the idea that the modulatory mechanism is fundamental to the human reward response and is not just an effect that is specific to clearly defined laboratory situations. This idea would be in line with findings showing that these modulations are mediated by rudimentary brain structures (Berridge, 2003; Salamone et al., 2009) and that they constitute a basic tendency that has widespread implications for research on motivation.

It is important to note that it is not likely that conscious reward decisions are affected by these irrelevant effort requirements. Specifically, conscious awareness of rewards may enable people to take into account the effort requirements of the specific course of action that leads to reward attainment. As the effort requirements in Experiment 3 are unrelated to attainment of the reward at stake, we do not expect people to make use of these in their conscious decisions about how much effort to invest. So, Experiment 3 tests the prediction that irrelevant effort requirements affect people's unconscious reward responses but not their conscious reward decisions (Hypothesis 3).

\section{Method}

Participants and design. Twenty participants (eight men, 12 women; mean age $=21.3$ years) were recruited to participate. They were paid the amount of money they earned during the experiment, which was on average $€ 3.60$. The study used a 2 (reward value: 1 cent vs. 10 cents) $\times 2$ (reward presentation: supraliminal vs. subliminal) $\times 2$ (task-irrelevant effort: low vs. high) within-subjects design, comprising 80 trials in total, 10 repetitions per condition. The task-irrelevant effort factor was manipulated by blocks. As such, participants completed five blocks in which effort requirements were low and five blocks in which effort requirements were high, in alternating order. The type of the first block (low task-irrelevant demands vs. high taskirrelevant demands) was counterbalanced across participants.

Apparatus. Handgrips were custom made of foam isolation material and steel. To make sure participants followed the instructions, handgrips were connected to the computer, eliciting a digital signal when they were squeezed. Participants indicated that squeezing the handgrip was effortful, at least to a moderate extent.

Procedure. Although the task context was strongly modified, the procedure of Experiment 3 was similar to that of Experiment 1. Specifically, in Experiment 3, effort requirements were not manipulated in the tapping task itself but via a secondary task that involved the handgrip. First, participants were familiarized with the handgrip by the experimenter, who made sure that they were able to adequately squeeze it. Participants were informed that we were interested in how people deal with different kinds of concurrent motor tasks. After participants had completed five practice trials, the experiment started. The time limit that participants had to meet to attain the reward was kept constant at $3.5 \mathrm{~s}$.

Trials. The sequence of events in a trial is depicted in Figure 1. In order, participants saw a fixation cross, the masks and the coin, and another fixation cross. After that, they saw a row of 25 open circles $(\mathrm{O})$, indicating to participants that they were to start tapping. With each tap, a circle turned into an $\mathrm{X}$, allowing participants to keep track of their progress. After tapping, they received feedback on their performance. On high task-irrelevanteffort blocks, participants squeezed the handgrip after the coin was presented. On low task-irrelevant-effort blocks, participants merely held the handgrip in their hand.

\section{Results and Discussion}

We analyzed the time in which participants completed 25 taps as a function of reward value, reward presentation, and taskirrelevant effort. Trials more than 3 standard deviations from the participant mean were deleted, which resulted in the exclusion of $1.0 \%$ of trials. ${ }^{4}$ Mean tapping times were submitted to a repeatedmeasures ANOVA according to the design (see Figure 6). This yielded a main effect of reward value, $F(1,19)=29.1, p<.001$, $\eta_{\mathrm{p}}^{2}=.61$, indicating that participants tapped faster when a more valuable reward was at stake. Moreover, the main effect of taskirrelevant effort was significant, $F(1,19)=5.1, p=.036, \eta_{\mathrm{p}}^{2}=$ .21 , indicating that participants generally tapped faster when they concurrently squeezed the handgrip. These effects were qualified by the Reward Value $\times$ Reward Presentation interaction, $F(1$, 19) $=15.0, p=.001, \eta_{\mathrm{p}}^{2}=.44$, that revealed that the effect of reward value was stronger on supraliminal trials. It is important to note that these findings were qualified by the Reward Value $x$ Reward Presentation $\times$ Task-Irrelevant Effort three-way interaction, $F(1,19)=4.4, p=.050, \eta_{\mathrm{p}}^{2}=.19$. To interpret this interaction and to test the hypothesis that task-irrelevant effort only affects sensitivity to unconscious rewards, we analyzed the effects of Reward Value $\times$ Task-Irrelevant Effort separately for supraliminally versus subliminally presented coins.

For supraliminal coins, there was a main effect of reward value, $F(1,19)=27.6, p<.001, \eta_{\mathrm{p}}^{2}=.59$, indicating that people worked harder for more valuable coins, and a main effect of task-irrelevant effort that approached significance, $F(1,19)=3.8, p=.068, \eta_{\mathrm{p}}^{2}=$ .17 , suggesting that people worked harder when they concurrently squeezed. It is interesting that these effects did not interact, $F<1$, suggesting that sensitivity to consciously perceived rewards is independent of the amount of incidentally expended effort.

\footnotetext{
${ }^{4}$ This procedure did not substantially alter our conclusions.
} 


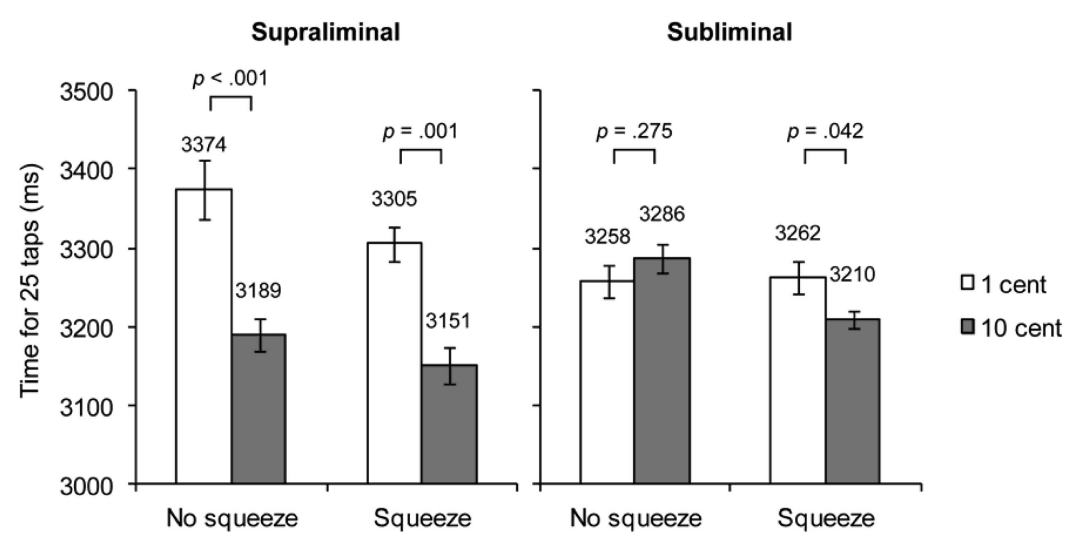

Figure 6. Results of Experiment 3. Mean tapping time (in milliseconds) for 25 taps is depicted as a function of reward value, reward presentation, and task-irrelevant effort. Error bars represent within-subjects standard errors of the mean (Cousineau, 2005).

For subliminal coins, there was again a modest effect of taskirrelevant effort, $F(1,19)=3.9, p=.063, \eta_{\mathrm{p}}^{2}=.17$, revealing that people worked harder when they concurrently squeezed. This effect was qualified by the Reward Value $\times$ Task-Irrelevant Effort interaction, $F(1,19)=6.3, p=.021, \eta_{\mathrm{p}}^{2}=.25$, which revealed that only when people exerted task-irrelevant effort did they tap faster for a high-value (vs. low-value) coin, $F(1,19)=4.8, p=$ $.042, \eta_{\mathrm{p}}^{2}=.20$ (other simple effect, $F<1.3$ ). As hypothesized, this finding demonstrates that incidentally expended effort makes people more sensitive to unconscious rewards.

Experiment 3 revealed that even when effort requirements are not instrumental to attaining a specific reward (in this case, squeezing a handgrip), they still affect people's unconscious responses to rewards. However, such irrelevant effort requirements do not affect conscious reward decisions. We discuss the implications of this finding in greater detail below.

\section{General Discussion}

In the current research, we tested the prediction that unconscious reward responses are attuned to the current effort requirements that are imposed on the body (Hypothesis 1). Across three experiments that used a finger-tapping paradigm, we found support for this idea. Our findings show that people act in line with the normative idea that the value of rewards becomes more important when rewards require more effort to attain. Thus, the main conclusion of the present work is that adaptive reward pursuit may take place without conscious awareness, albeit in a basic way.

We found evidence for this modulatory mechanism with various ways of manipulating effort requirements across three experiments. In Experiment 1, people received overt instructions that the upcoming block would require either little or much effort. Results indicated that people responded more strongly to high-value rewards on blocks in which more effort was required. We replicated this pattern of results in Experiment 2, in which people could detect effort requirements only while they were carrying out the task. This finding lent support for the idea that reward responses are dynamically modulated by current information about effort requirements and are not just predefined consequences of the effort-demanding context. We pushed the idea another step further in Experiment 3 by manipulating effort requirements such that they were unrelated to the reward that could be earned. During task performance, participants either did or did not concurrently squeeze a handgrip with their other hand to test whether the bodily experience of effort is sufficient to make people more reward sensitive on an unconscious level. This proved to be the case. Because people were given no conscious reasons to integrate effort requirements and rewards, Experiment 3 excluded the possibility that unconscious modulations were only observed because they were consciously prepared via the task instructions. Instead, this finding suggests that unconscious modulations are a basic human tendency that may well have ubiquitous implications for human cognition and behavior.

Additionally, the present work shows that consciousness of rewards can adjust or even overrule the basic modulatory mechanism. First, conscious processes suspend the expense of effort when a reward is not sufficiently valuable to cover for the requirements (Brehm \& Self, 1989; Gendolla et al., 2011). More specifically, in support of Hypothesis 2, we found that only in response to consciously perceived rewards that are relatively low in value do people make the decision to stop expending effort. This phenomenon was most pronounced in the face of high effort requirements (Experiment 2). This finding is consistent with research on consciousness that suggests that the information carried by stimuli is only used for strategic decisions if they are perceived with conscious awareness (Baars, 2002; Dehaene \& Naccache, 2001). Indeed, actively curbing effort may require conscious control, and it therefore makes sense that this effort minimization only occurred in response to consciously perceived rewards. Furthermore, in line with Hypothesis 3, we found support for the idea that conscious reward decisions take into account not just any current effort requirements; rather, they only take effort requirements into account when these are, in fact, relevant to attaining a reward. Enabling more advanced processes, consciousness thus seems to support a more sophisticated mode of reward pursuit that serves to save effort beyond the modulations of reward sensitivity that can also occur without awareness.

As to the nature of these more advanced processes, it may be fruitful to conceptualize these processes in terms of calculations of 
expected value (EV), which may be made only on the basis of conscious reward information. Specifically, this conceptualization would suggest that EV is lowest in the supraliminal low-reward condition ( 1 cent), somewhat higher in the subliminal conditions as people do not know what is at stake (5.5 cents-i.e., the average of 1 and 10 cents), and highest in the supraliminal high-reward condition (10 cents). Assuming that our participants were indifferent toward earning 1 cent (but not to earning 5.5 or 10 cents), this interpretation can thus explain why they refrained from investing effort only for consciously perceived, low-value rewards. ${ }^{5}$ Moreover, because EV calculations are thought to pertain to the specific course of action that leads to reward attainment (Eccles \& Wigfield, 2002; see also Brehm \& Self, 1989), such an approach would suggest that irrelevant effort requirements are unlikely to be incorporated in conscious reward decisions, which is in line with our rationale and our findings. It should be noted that this EVbased interpretation does not challenge or qualify our main proposal on the operation of unconscious processes in reward pursuit, as people's performance was still sensitive to differences in value of subliminal rewards when required effort was high (see Bargh \& Morsella, 2008). Nevertheless, it does help to more precisely characterize the nature of the conscious processes that are involved

This account of the specific role of consciousness resonates well with the idea that the calculated anticipation of events beyond the immediate future is an ability specific to humans (Gilbert \& Wilson, 2007; Suddendorf, Addis, \& Corballis, 2009), likely associated with conscious processes. Although the rudimentary mechanism may operate well when it comes to rewards that are actually present in the environment (most animals act predominantly on these), conscious reward pursuit seems to also take the future into account, as saving effort when rewards of little value are at stake may facilitate performance on subsequent, more fruitful tasks. This idea is also consistent with the findings from Experiment 3. In this experiment, task-irrelevant effort requirements were integrated with rewards on an unconscious level, but this integration was no longer present when coins were perceived with conscious awareness. Again, when it comes to rewards that are currently present in the environment, the rudimentary mechanism probably does a good job, as current effort requirements should in most cases pertain to rewards that are currently present. Conscious awareness, in turn, may aid in shielding reward pursuit from unwanted, irrelevant influences-again, this is an ability that is especially useful for the pursuit of rewards that are further away, either in time or in space. Although this explanation is admittedly speculative, the present findings clearly show that when rewards permeate consciousness, control processes that serve adaptive reward pursuit in an even more advanced way are triggered (see Bijleveld et al., 2010; Dehaene \& Naccache, 2001).

\section{Theoretical Implications}

On the surface, the current work seems to bear relation to the phenomenon of effort discounting. This phenomenon entails that when a certain course of action is anticipated to lead to effort requirements, this course of action is valued less (e.g., as reflected by reduced activity in the striatum; Botvinick, Huffstetler, \& McGuire, 2009; Croxson, Walton, O'Reilly, Behrens, \& Rushworth, 2009) and, after repeated exposure, is avoided (Hull, 1943;
Kurniawan et al., 2010). Thus, as does the present research, these studies address the integration of information about reward value and effort requirements. Nevertheless, the outcome of effort discounting (i.e., choosing effortful options less often) seems to be the opposite of the present findings, in which people applied more effort in the face of higher demands. This apparent contrast was previously noted by Botvinick and Rosen (2009), who proposed that anticipated effort requirements not only induce people to avoid effortful choices but also serve a second important function-that is, to prepare for the application of effort in the face of actual demanding situations. The present work focuses on this second function and is novel in showing that anticipations modulate the human reward response via a rudimentary mechanism, aiding adaptive effort recruitment. Taken together, the mechanism that is addressed by the current work is markedly different from effort discounting due to its distinct functionality.

Nevertheless, an interesting similarity between these two lines of research is that both have increasingly focused on the role of unconscious processes. For example, work on effort discounting has recently shown that people do not need to be aware of differences in effort requirements between choice options to still develop a preference for less-demanding options (Kool, McGuire, Rosen, \& Botvinick, 2010) Also here, rudimentary mechanisms likely play a vital role. It should be noted, however, that the avoidance of effortful choices is best accounted for by (implicit) learning processes, as people's aversion to effortful choices seems to develop over the course of time (see also Pessiglione et al., 2008). Instead, the current work addresses a mechanism that directly responds to momentary effort requirements. Although from different points of view, these recent developments raise the interesting question of how decisions are shaped by rudimentary functions. One could, for example, predict that unconscious integrations gain importance when conscious control processes are less available or less relevant (e.g., under load or under threat; see Hester \& Garavan, 2005; Inzlicht, McKay, \& Aronson, 2006; Ramirez \& Beilock, 2011).

A related issue is raised by the finding that currently experienced effort requirements can modulate reward sensitivity through a low-level mechanism, even when effort requirements cannot be consciously anticipated (Experiment 2). Do these anticipations (Experiment 1), then, still make use of the same low-level mechanism? This issue may be understood and examined in the context of theories of embodied cognition (Barsalou, 1999, 2009; Niedenthal et al., 2005) that propose that knowledge of the world is represented in simulators, that is, neural structures that store sensory, motor, affective, and other bodily reactions. According to this idea, merely retrieving a concept (or merely anticipating an action) activates the simulators that are also involved in actual perceptual experiences with that object. In the context of the present work, one could well interpret anticipations of effort requirements as a simulation of actual effort requirements. Regardless of how the activation of this embodied representation occurs (i.e., whether via actual effort requirements or via anticipations; see Morewedge, Huh, \& Vosgerau, 2010), the effects on reward sensitivity may well be the same. By drawing from such theory, it can thus be better understood why anticipations and actual effort

\footnotetext{
${ }^{5}$ We thank one of the reviewers for pointing out this possibility to us
} 
have the same consequences. Consistent with the current data, one might speculate that it is not the anticipation or the actual effort per se but the activation of this embodied, low-level representation of effort that makes people more reward sensitive on an unconscious level.

\section{Future Directions}

As the effects on reward sensitivity thus turn out to be easily triggered, they are likely to be ubiquitous, carrying implications for other fields of research. One such field pertains to selfregulation, an area that focuses on how people control their impulses toward rewards such as food. Although the initial behavioral response toward palatable food generally is to approach it (and then to eat it), people may rely on conscious control processes to resist this temptation (Fishbach \& Shah, 2006; Muraven \& Baumeister, 2000). Theories of impulse control have largely focused on the control side of this process (e.g., when people use control processes most effectively), but the impulses themselves have received relatively little research attention, in spite of their clear predictive importance (Hofmann, Friese, \& Strack, 2009; Veling \& Aarts, 2011). The present work suggests that effort requirements (more specifically, the activation of their bodily representation; Barsalou, 2009) may be an important moderator of the strength of impulses toward rewarding stimuli. After all, the rudimentary system that produces this response is aimed not only at approaching rewarding items but also at conserving effort.

More generally, this rudimentary system is implicated in many aspects of cognition and behavior, not just the ones discussed above. Accordingly, the consequences of the basic integration of effort requirements and rewards likely extend to various motivational cues, not just those related to money (and food). In spite of their diversity, many subfields of psychology include motivational factors that are, in turn, often conceptualized in terms of rewards and demands. Thus, it is well possible that the rudimentary motivational system that we have addressed supports functions, for example, related to the pursuit of goals (Bargh, Gollwitzer, LeeChai, Barndollar, \& Trötschel, 2001; Custers \& Aarts, 2010), the experience of free will (Aarts et al., 2012; Preston \& Wegner, 2007), perceptual judgments (Balcetis \& Dunning, 2006; Proffitt, 2006), risk taking (Knutson, Wimmer, Kuhnen, \& Winkielman, 2008), social behavior (Santamaria \& Rosenbaum, 2011), and judgments of value (Higgins, 2006; Kruger, Wirtz, Van Boven, \& Altermatt, 2004). Future research should examine whether and how effort requirements affect these domains; in the meantime, the present work implies that effort requirements need to be studied along with rewards and that in their integration, unconscious processes may well play a lead role.

\section{References}

Aarts, H., Bijleveld, E., Custers, R., Dogge, M., Deelder, M., Schutter, D., \& van Haren, N. E. M. (2012). Positive priming and intentional binding: Eye blink rate predicts reward information effects on the sense of agency. Social Neuroscience, 7, 105-112.doi:10.1080/17470919.2011.590602

Aarts, H., \& Dijksterhuis, A. (2003). The silence of the library: Environment, situational norm, and social behavior. Journal of Personality and Social Psychology, 84, 18-28. doi:10.1037/0022-3514.84.1.18

Ariely, D., Gneezy, U., Loewenstein, G., \& Mazar, N. (2009). Large stakes and big mistakes. Review of Economic Studies, 76, 451-469. doi: 10.1111/j.1467-937X.2009.00534.X

Aston-Jones, G., \& Cohen, J. D. (2005). An integrative theory of locus coeruleus-norepinephrine function: Adaptive gain and optimal performance. Annual Review of Neuroscience, 28, 403-450. doi:10.1146/ annurev.neuro.28.061604.135709

Baars, B. J. (2002). The conscious access hypothesis: Origins and recent evidence. Trends in Cognitive Sciences, 6, 47-52. doi:10.1016/S13646613(00)01819-2

Balcetis, E., \& Dunning, D. (2006). See what you want to see: Motivational influences on visual perception. Journal of Personality and Social Psychology, 91, 612-625. doi:10.1037/0022-3514.91.4.612

Bargh, J. A., Gollwitzer, P. M., Lee-Chai, A., Barndollar, K., \& Trötschel, R. (2001). The automated will: Nonconscious activation and pursuit of behavioral goals. Journal of Personality and Social Psychology, 81, 1014-1027. doi:10.1037/0022-3514.81.6.1014

Bargh, J. A., Gollwitzer, P. M., \& Oettingen, G. (2010). Motivation. In S. T. Fiske, D. T. Gilbert, \& G. Lindzey (Eds.), Handbook of social psychology (5th ed., pp. 268-316). New York, NY: Wiley.

Bargh, J. A., \& Morsella, E. (2008). The unconscious mind. Perspectives on Psychological Science, 3, 73-79. doi:10.1111/j.17456916.2008.00064.x

Barsalou, L. W. (1999). Perceptual symbol systems. Behavioral and Brain Sciences, 22, 577-660. doi:10.1017/S0140525X99532147

Barsalou, L. W. (2009). Simulation, situated conceptualization, and prediction. Philosophical Transactions of the Royal Society, Series B: Biological Sciences, 364, 1281-1289. doi:10.1098/rstb.2008.0319

Beilock, S. (2010). Choke: What the secrets of the brain reveal about getting it right when you have to. New York, NY: Simon and Schuster.

Berridge, K. C. (2003). Irrational pursuits: Hyper-incentives from a visceral brain. In I. Brocas \& J. Carillo (Eds.), The psychology of economic decisions (Vol. 1, pp. 17-40). New York, NY: Oxford University Press.

Bijleveld, E., Custers, R., \& Aarts, H. (2009). The unconscious eye-opener: Pupil size reveals strategic recruitment of resources upon presentation of subliminal reward cues. Psychological Science, 20, 1313-1315. doi: 10.1111/j.1467-9280.2009.02443.x

Bijleveld, E., Custers, R., \& Aarts, H. (2010). Unconscious reward cues increase invested effort, but do not change speed-accuracy tradeoffs. Cognition, 115, 330-335. doi:10.1016/j.cognition.2009.12.012

Bijleveld, E., Custers, R., \& Aarts, H. (2011). Once the money is in sight: Distinctive effects of conscious and unconscious rewards on task performance. Journal of Experimental Social Psychology, 47, 865-869. doi:10.1016/j.jesp.2011.03.002

Bijleveld, E., Custers, R., \& Aarts, H. (in press). Human reward pursuit: From rudimentary to higher-level functions. Current Directions in Psychological Science.

Bjork, J. M., \& Hommer, D. W. (2007). Anticipating instrumentally obtained and passively-received rewards: A factorial fMRI investigation. Behavioural Brain Research, 177, 165-170. doi:10.1016/ j.bbr.2006.10.034

Bonner, S. E., \& Sprinkle, G. B. (2002). The effects of monetary incentives on effort and task performance: Theories, evidence, and a framework for research. Accounting, Organizations and Society, 27, 303-345. doi: 10.1016/S0361-3682(01)00052-6

Botvinick, M. M., Huffstetler, S., \& McGuire, J. T. (2009). Effort discounting in human nucleus accumbens. Cognitive, Affective, \& Behavioral Neuroscience, 9, 16-27. doi:10.3758/CABN.9.1.16

Botvinick, M. M., \& Rosen, Z. B. (2009). Anticipation of cognitive demand during decision-making. Psychological Research, 73, 835-842. doi:10.1007/s00426-008-0197-8

Bouton, M. E. (1993). Context, time, and memory retrieval in the interference paradigms of Pavlovian learning. Psychological Bulletin, 114, 80-99. doi:10.1037/0033-2909.114.1.80

Brehm, J. W., \& Self, E. A. (1989). The intensity of motivation. Annual 
Review of Psychology, 40, 109-131. doi:10.1146/annurev.ps.40 020189.000545

Camerer, C. F., \& Hogarth, R. M. (1999). The effects of financial incentives in experiments: A review and capital-labor-production framework. Journal of Risk and Uncertainty, 19, 7-42. doi:10.1023/A:1007850605129

Capa, R. L., Bustin, G. M., Cleeremans, A., \& Hansenne, M. (2011). Conscious and unconscious reward cues can affect a critical component of executive control: (Un)conscious updating? Experimental Psychology, 58, 370-375. doi:10.1027/1618-3169/a000104

Cousineau, D. (2005). Confidence intervals in within-subject designs: A simpler solution to Loftus and Masson's method. Tutorials in Quantitative Methods for Psychology, 1, 42-45.

Croxson, P. L., Walton, M. E., O'Reilly, J. X., Behrens, T. E. J., \& Rushworth, M. F. S. (2009). Effort-based cost-benefit valuation and the human brain. Journal of Neuroscience, 29, 4531-4541. doi:10.1523/ JNEUROSCI.4515-08.2009

Custers, R., \& Aarts, H. (2010, July 2). The unconscious will: How the pursuit of goals operates outside of conscious awareness. Science, 329, 47-50. doi:10.1126/science.1188595

Dehaene, S., Changeux, J.-P., Naccache, L., Sackur, J., \& Sergent, C. (2006). Conscious, preconscious, and subliminal processing: A testable taxonomy. Trends in Cognitive Sciences, 10, 204-211. doi:10.1016/ j.tics.2006.03.007

Dehaene, S., \& Naccache, L. (2001). Towards a cognitive neuroscience of consciousness: Basic evidence and a workspace framework. Cognition, 79, 1-37. doi:10.1016/S0010-0277(00)00123-2

Delgado, M. R. (2007). Reward-related responses in the human striatum. In B. W. Balleine, K. Doya, J. O'Doherty, \& M. Sakagami (Eds.), Annals of the New York Academy of Sciences: Vol. 1104. Reward and decision making in corticobasal ganglia networks (pp. 70-88). doi:10.1196/ annals. 1390.002

Donald, M. (2001). A mind so rare: The evolution of human consciousness. New York, NY: Norton.

Eccles, J. S., \& Wigfield, A. (2002). Motivational beliefs, values, and goals. Annual Review of Psychology, 53, 109-132. doi:10.1146/ annurev.psych.53.100901.135153

Eisenberger, R., \& Aselage, J. (2009). Incremental effects of reward on experienced performance pressure: Positive outcomes for intrinsic interest and creativity. Journal of Organizational Behavior, 30, 95-117. doi:10.1002/job.543

Engelmann, J. B., \& Pessoa, L. (2007). Motivation sharpens exogenous spatial attention. Emotion, 7, 668-674. doi:10.1037/1528-3542.7.3.668

Epley, N., Keysar, B., Van Boven, L., \& Gilovich, T. (2004). Perspective taking as egocentric anchoring and adjustment. Journal of Personality and Social Psychology, 87, 327-339. doi:10.1037/0022-3514.87.3.327

Eubanks, L., Wright, R. A., \& Williams, B. J. (2002). Reward influence on the heart: Cardiovascular response as a function of incentive value at five levels of task demand. Motivation and Emotion, 26, 139-152. doi:10.1023/A:1019863318803

Feather, N. T. (Ed.). (1982). Expectations and actions: Expectancy-value models in psychology. Hillsdale, NJ: Erlbaum.

Fishbach, A., \& Shah, J. Y. (2006). Self-control in action: Implicit dispositions toward goals and away from temptations. Journal of Personality and Social Psychology, 90, 820-832. doi:10.1037/0022-3514.90.5.820

Gawronski, B., Rydell, R. J., Vervliet, B., \& De Houwer, J. (2010). Generalization versus contextualization in automatic evaluation. Journal of Experimental Psychology: General, 139, 683-701. doi:10.1037/ a0020315

Gendolla, G. H. E., Wright, R. A., \& Richter, M. (2011). Effort intensity: Some insights from the cardiovascular system. In R. Ryan (Ed.), The Oxford handbook of motivation (pp. 420-438). New York, NY: Oxford University Press.

Gilbert, D. T., Pelham, B. W., \& Krull, D. S. (1988). On cognitive busyness: When person perceivers meet persons perceived. Journal of
Personality and Social Psychology, 54, 733-740. doi:10.1037/00223514.54.5.733

Gilbert, D. T., \& Wilson, T. D. (2007, September 7). Prospection: Experiencing the future. Science, 317, 1351-1354. doi:10.1126/science .1144161

Glucksberg, S. (1962). The influence of strength of drive on functional fixedness and perceptual recognition. Journal of Experimental Psychology, 63, 36-41. doi:10.1037/h0044683

Hester, R., \& Garavan, H. (2005). Working memory and executive function: The influence of content and load on the control of attention Memory \& Cognition, 33, 221-233. doi:10.3758/BF03195311

Higgins, E. T. (2006). Value from hedonic experience and engagement Psychological Review, 113, 439-460. doi:10.1037/0033-295X.113.3.439

Hofmann, W., Friese, M., \& Strack, F. (2009). Impulse and self-control from a dual-systems perspective. Perspectives on Psychological Science, 4, 162-176. doi:10.1111/j.1745-6924.2009.01116.x

Hull, C. L. (1943). Principles of behavior. New York, NY: AppletonCentury-Crofts.

Inzlicht, M., McKay, L., \& Aronson, J. (2006). Stigma as ego depletion: How being the target of prejudice affects self-control. Psychological Science, 17, 262-269. doi:10.1111/j.1467-9280.2006.01695.x

Jostmann, N. B., Lakens, D., \& Schubert, T. W. (2009). Weight as an embodiment of importance. Psychological Science, 20, 1169-1174. doi:10.1111/j.1467-9280.2009.02426.x

Kiss, M., Driver, J., \& Eimer, M. (2009). Reward priority of visual target singletons modulates event-related potential signatures of attentional selection. Psychological Science, 20, 245-251. doi:10.1111/j.14679280.2009.02281.x

Knutson, B., Delgado, M. R., \& Phillips, P. E. M. (2008). Representation of subjective value in the striatum. In P. W. Glimcher, C. F. Camerer, E. Fehr, \& R. A. Poldrack (Eds.), Neuroeconomics: Decision making and the brain (pp. 389-406). Oxford, United Kingdom: Oxford University Press.

Knutson, B., Wimmer, G. E., Kuhnen, C. M., \& Winkielman, P. (2008) Nucleus accumbens activation mediates the influence of reward cues on financial risk taking. NeuroReport, 19, 509-513. doi:10.1097/ WNR.0b013e3282f85c01

Kool, W., McGuire, J. T., Rosen, Z. B., \& Botvinick, M. M. (2010). Decision making and the avoidance of cognitive demand. Journal of Experimental Psychology: General, 139, 665-682. doi:10.1037/ a0020198

Krebs, R. M., Boehler, C. N., \& Woldorff, M. G. (2010). The influence of reward associations on conflict processing in the Stroop task. Cognition, 117, 341-347. doi:10.1016/j.cognition.2010.08.018

Kruger, J., Wirtz, D., Van Boven, L., \& Altermatt, T. W. (2004). The effort heuristic. Journal of Experimental Social Psychology, 40, 91-98. doi: 10.1016/S0022-1031(03)00065-9

Kurniawan, I. T., Seymour, B., Talmi, D., Yoshida, W., Chater, N., \& Dolan, R. J. (2010). Choosing to make an effort: The role of striatum in signaling physical effort of a chosen action. Journal of Neurophysiology, 104, 313-321. doi:10.1152/jn.00027.2010

Lamme, V. A. F. (2006). Towards a true neural stance on consciousness. Trends in Cognitive Sciences, 10, 494-501. doi:10.1016/j.tics.2006 .09 .001

Lau, H., \& Rosenthal, D. (2011). Empirical support for higher-order theories of conscious awareness. Trends in Cognitive Sciences, 15, 365-373. doi:10.1016/j.tics.2011.05.009

Marcora, S. (2009). Perception of effort during exercise is independent of afferent feedback from skeletal muscles, heart, and lungs. Journal of Applied Physiology, 106, 2060-2062. doi:10.1152/japplphysiol.90378.2008

Morewedge, C. K., Huh, Y. E., \& Vosgerau, J. (2010, December 10). Thought for food: Imagined consumption reduces actual consumption. Science, 330, 1530-1533. doi:10.1126/science.1195701

Muraven, M., \& Baumeister, R. F. (2000). Self-regulation and depletion of 
limited resources: Does self-control resemble a muscle? Psychological Bulletin, 126, 247-259. doi:10.1037/0033-2909.126.2.247

Niedenthal, P. M., Barsalou, L. W., Winkielman, P., Krauth-Gruber, S., \& Ric, F. (2005). Embodiment in attitudes, social perception, and emotion. Personality and Social Psychology Review, 9, 184-211. doi:10.1207/ s15327957pspr0903_1

Pessiglione, M., Petrovic, P., Daunizeau, J., Palminteri, S., Dolan, R. J., \& Frith, C. D. (2008). Subliminal instrumental conditioning demonstrated in the human brain. Neuron, 59, 561-567. doi:10.1016/j.neuron.2008.07.005

Pessiglione, M., Schmidt, L., Draganski, B., Kalisch, R., Lau, H., Dolan, R. J., \& Frith, C. D. (2007, April 12). How the brain translates money into force: A neuroimaging study of subliminal motivation. Science, 316, 904-906. doi:10.1126/science.1140459

Phillips, P. E. M., Walton, M. E., \& Jhou, T. J. (2007). Calculating utility: Preclinical evidence for cost-benefit analysis by mesolimbic dopamine. Psychopharmacology, 191, 483-495. doi:10.1007/s00213-006-0626-6

Preston, J., \& Wegner, D. M. (2007). The eureka error: Inadvertent plagiarism by misattributions of effort. Journal of Personality and Social Psychology, 92, 575-584. doi:10.1037/0022-3514.92.4.575

Preston, J., \& Wegner, D. M. (2009). Elbow grease: When action feels like work. In E. Morsella, J. A. Bargh, \& P. M. Gollwitzer (Eds.), Oxford handbook of human action (pp. 569-586). New York, NY: Oxford University Press.

Proffitt, D. R. (2006). Embodied perception and the economy of action. Perspectives on Psychological Science, 1, 110-122. doi:10.1111/j.17456916.2006.00008.x

Ramirez, G., \& Beilock, S. L. (2011, January 14). Writing about testing worries boosts exam performance in the classroom. Science, 331, 211213. doi:10.1126/science.1199427

Salamone, J. D., Correa, M., Farrar, A. M., Nunes, E. J., \& Pardo, M. (2009). Dopamine, behavioral economics, and effort. Frontiers in Behavioral Neuroscience, 3, 13. doi:10.3389/neuro.08.013.2009

Salamone, J. D., Cousins, M. S., McCullough, L. D., Carriero, D. L., \& Berkowitz, R. J. (1994). Nucleus accumbens dopamine release increases during instrumental lever pressing for food but not free food consumption. Pharmacology Biochemistry and Behavior, 49, 25-31. doi: 10.1016/0091-3057(94)90452-9

Santamaria, J. P., \& Rosenbaum, D. A. (2011). Etiquette and effort: Holding doors for others. Psychological Science, 22, 584-588. doi: 10.1177/0956797611406444

Schmidt, L., Palminteri, S., Lafargue, G., \& Pessiglione, M. (2010). Splitting motivation: Unilateral effects of subliminal incentives. Psychological Science, 21, 977-983. doi:10.1177/0956797610372636

Strack, F., \& Deutsch, R. (2004). Reflective and impulsive determinants of social behavior. Personality and Social Psychology Review, 8, 220-247. doi:10.1207/s15327957pspr0803_1

Suddendorf, T., Addis, D. R., \& Corballis, M. C. (2009). Mental time travel and the shaping of the human mind. Philosophical Transactions of the Royal Society, Series B: Biological Sciences, 364, 1317-1324. doi: 10.1098/rstb.2008.0301

Treadway, M. T., Buckholtz, J. W., Schwartzman, A. N., Lambert, W. E., \& Zald, D. H. (2009). Worth the "EEfRT"? The effort expenditure for rewards task as an objective measure of motivation and anhedonia. PLoS ONE, 4(8), Article e6598. doi:10.1371/journal.pone.0006598

van den Bos, R., van der Harst, J., Jonkman, S., Schilders, M., \& Spruijt, B. (2006). Rats assess costs and benefits according to an internal standard. Behavioural Brain Research, 171, 350-354. doi:10.1016/ j.bbr.2006.03.035

Van den Bussche, E., Segers, G., \& Reynvoet, B. (2008). Conscious and unconscious proportion effects in masked priming. Consciousness and Cognition, 17, 1345-1358. doi:10.1016/j.concog.2007.08.005

Veling, H., \& Aarts, H. (2010). Cueing task goals and earning money: Relatively high monetary rewards reduce failures to act on goals in a Stroop task. Motivation and Emotion, 34, 184-190. doi:10.1007/ s11031-010-9160-2

Veling, H., \& Aarts, H. (2011). Changing impulsive determinants of unhealthy behaviours toward rewarding objects. Health Psychology Review, 5, 150-153. doi:10.1080/17437199.2010.539970

Wallis, J. D., \& Kennerley, S. W. (2010). Heterogeneous reward signals in prefrontal cortex. Current Opinion in Neurobiology, 20, 191-198. doi: 10.1016/j.conb.2010.02.009

Walton, M. E., Kennerley, S. W., Bannerman, D. M., Phillips, P. E., \& Rushworth, M. F. (2006). Weighing up the benefits of work: Behavioral and neural analyses of effort-related decision making. Neural Networks, 19, 1302-1314. doi:10.1016/j.neunet.2006.03.005

Watanabe, M. (2007). Role of anticipated reward in cognitive behavioral control. Current Opinion in Neurobiology, 17, 213-219. doi:10.1016/ j.conb.2007.02.007

Wittenbrink, B., Judd, C. M., \& Park, B. (2001). Spontaneous prejudice in context: Variability in automatically activated attitudes. Journal of Personality and Social Psychology, 81, 815-827. doi:10.1037/00223514.81.5.815

Wright, R. A. (2008). Refining the prediction of effort: Brehm's distinction between potential motivation and motivation intensity. Social and Personality Psychology Compass, 2, 682-701. doi:10.1111/j.17519004.2008.00093.x

Zedelius, C. M., Veling, H., \& Aarts, H. (2011). Boosting or choking: How conscious and unconscious reward processing modulate the active maintenance of goal-relevant information. Consciousness and Cognition, 20, 355-362. doi:10.1016/j.concog.2010.05.001

Received May 30, 2011

Revision received January 18, 2012 Accepted January 18, 2012 